\title{
Rhinosporidiosis of Trachea: A Rare Encounter
}

\author{
${ }^{1}$ Ruchir Dhawan, ${ }^{2}$ Rahul Kawatra, ${ }^{3}$ Charu Singh, ${ }^{4}$ Sachin Khanduri, ${ }^{5}$ Nirupama Lal \\ ${ }^{6}$ Shiv Sagar Gupta, ${ }^{7}$ Puneet Maheshwari \\ ${ }^{1}$ Assistant Professor, Department of Otorhinolaryngology and Head and Neck Surgery, Era's Lucknow Medical College and Hospital \\ Lucknow, Uttar Pradesh, India \\ ${ }^{2}$ Professor and Head, Department of Otorhinolaryngology, Era's Lucknow Medical College and Hospital, Lucknow, Uttar Pradesh, India \\ ${ }^{3}$ Assistant Professor, Department of Otorhinolaryngology, Era's Lucknow Medical College and Hospital, Lucknow, Uttar Pradesh, India \\ ${ }^{4}$ Associate Professor, Department of Radiology, Era's Lucknow Medical College and Hospital, Lucknow, Uttar Pradesh, India \\ ${ }^{5}$ Associate Professor, Department of Pathology, Era's Lucknow Medical College and Hospital, Lucknow, Uttar Pradesh, India \\ ${ }^{6}$ Associate Professor, Department of Pulmonology, Era's Lucknow Medical College and Hospital, Lucknow, Uttar Pradesh, India \\ ${ }^{7}$ Junior Resident, Department of Otorhinolaryngology, Era's Lucknow Medical College and Hospital, Lucknow, Uttar Pradesh, India
}

Correspondence: Ruchir Dhawan, Assistant Professor, Department of Otorhinolaryngology and Head and Neck Surgery, Era's Lucknow Medical College and Hospital, Lucknow, Uttar Pradesh, India, e-mail: ruchir_dhawan@yahoo.com

\section{ABSTRACT}

Rhinosporidiosis, which is a chronic fungal granulomatous disease, is caused by Rhinosporidium seeberi, a protistal microbe. It is a disease affecting primarily the mucosa of nose, conjunctiva and urethra. We are reporting an extremely rare case of tracheal rhinosporidiosis from the northern part of the Indian subcontinent which presented to us as case of respiratory stridor with hemoptysis and was properly investigated following which complete excision of the tracheal mass was done by bronchoscopy.

Keywords: Tracheal rhinosporidiosis, Rhinosporidium seeberi, Bronchoscopy, Stridor.

\section{INTRODUCTION}

Rhinosporidiosis is a chronic granulomatous infection of the mucous membrane initially described by Seeber in 1990, and the various sites of involvement other than the nose and conjunctiva are the pharynx, anus, penis, vagina, ears, larynx and skin. ${ }^{1,2}$ Rhinosporidiosis manifests as a polypoidal, soft mass sometimes pedunculated growing inside the affected tissue cavity and surgical excision is the gold standard treatment. Lesion in the trachea is extremely rare though we are reporting it from an endemic zone. Tracheal lesion after complete excision was cauterized.

\section{CASE REPORT}

A 52-year-old male reported in the Emergency Department of Era's Lucknow Medical College and Hospital, Lucknow, late in the afternoon with the chief complaints of stridor and hemoptysis for 1 month which aggravated 24 hours ago, ENT resident on duty attended the emergency. History revealed that patient had difficulty in breathing along with bleeding in cough for a month for which he consulted a private practitioner and had undergone series of X-rays of neck and chest, which revealed nothing. The worsening stridor and hemoptysis brought the patient to our emergency. Oropharyngeal and laryngeal examination was uneventful and nothing could be revealed. Patient was immediately taken up for bronchoscopic examination in coordination with the department of pulmonary medicine. Flexible bronchoscopy revealed a soft polypoidal mass present 1 to $2 \mathrm{~cm}$ above the carina at the tracheal base which bled on probing (Fig. 1). The pedunculated $3 \times 4 \mathrm{~cm}$ exophytic tracheal mass was moving up and down on respiration just touching the 2 to $2.5 \mathrm{~cm}$ tracheal lumen. A computed tomographic scan of the thorax showed polypoidal mass just $1.5 \mathrm{~cm}$ above the carina (Fig. 2). Rigid bronchoscopy was done under general anesthesia and the red colored polypoidal mass was completely resected with absolute homeostasis (Fig. 3). Histopathological examination of the

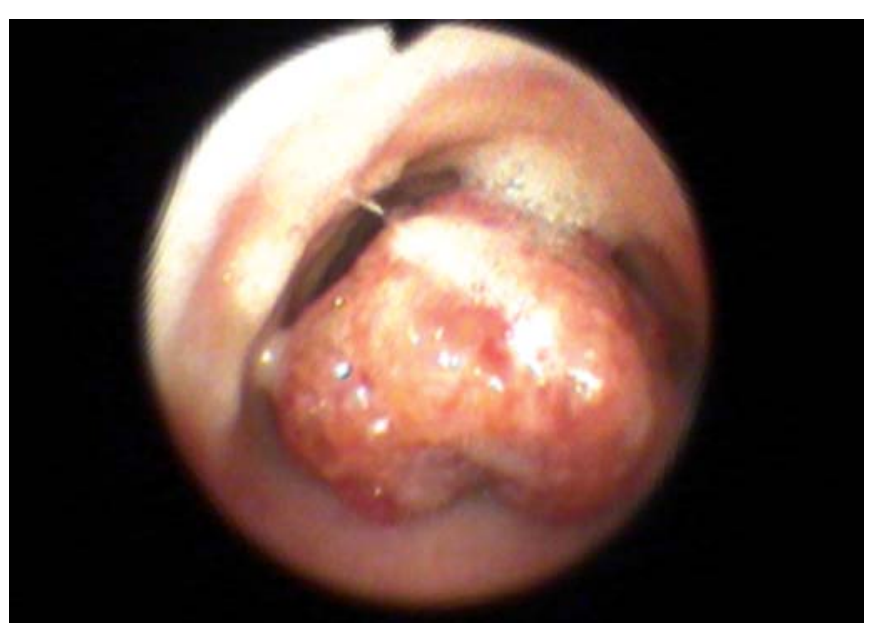

Fig. 1: Flexible bronchoscopy showing a soft polypoidal mass present 1 to $2 \mathrm{~cm}$ 
tissue showed several sporangia which prove the diagnosis of rhinosporidiosis (Fig. 4).

\section{DISCUSSION}

It is documented that rhinosporidiosis is a chronic granulomatous disease in South India, Sri Lanka and some other

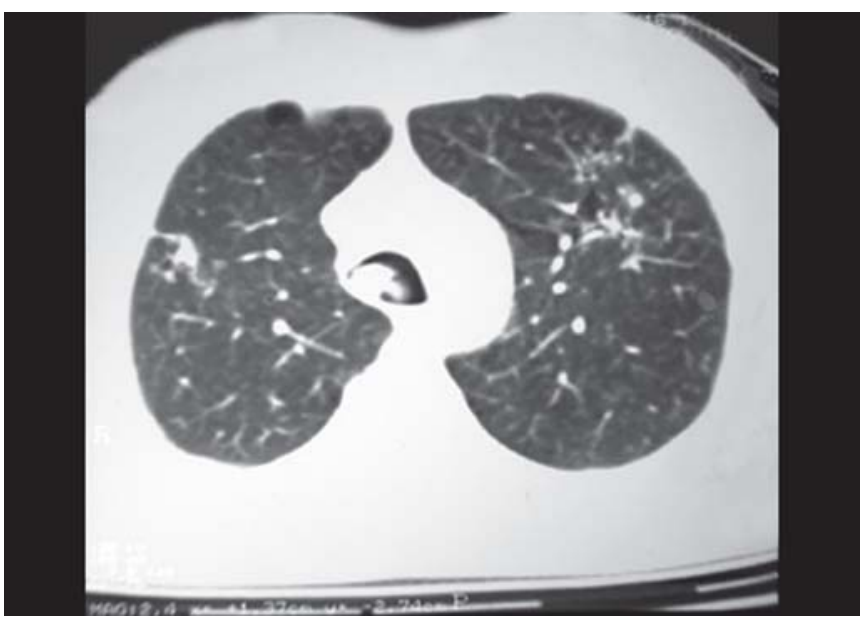

Fig. 2: Tracheal lumen showing polypoidal mass in computed tomographic scan

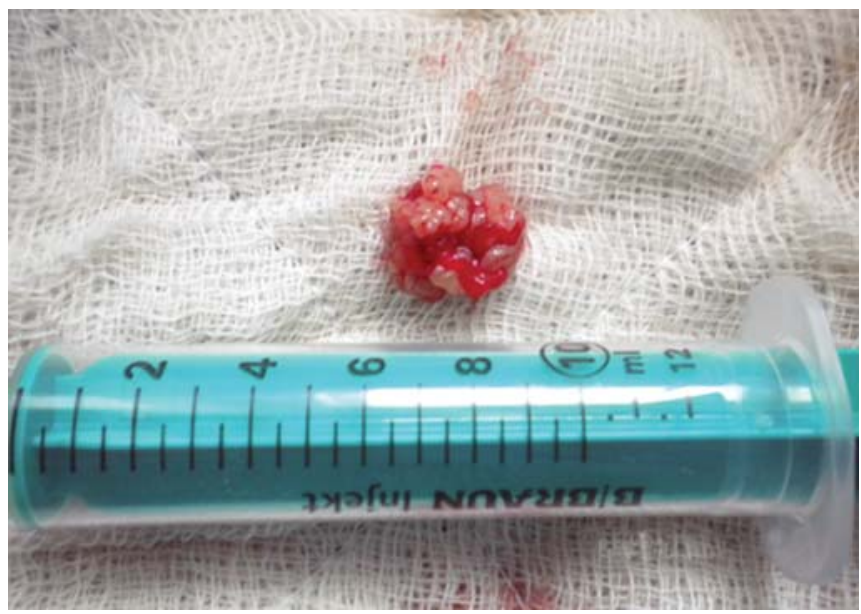

Fig. 3: Flexible bronchoscopy showing a soft polypoidal mass present 1 to $2 \mathrm{~cm}$

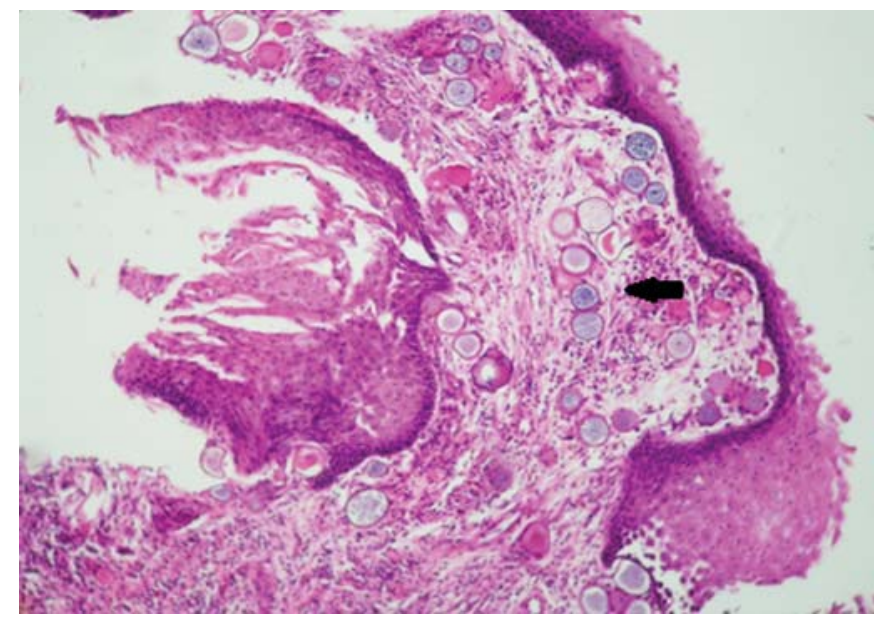

Fig. 4: Sporangia seen in histology of rhinosporidial mass areas of the African continent with European outbreaks, ${ }^{3}$ and is caused by Rhinosporidiosis seeberi a protistal microbe in the newly described class Mesomycetozoea at the animalfungal boundary. Transmission of $R$. seeberi in human beings may be due to exposure of its spores through dust, fomites and contact with spores bearing contaminated stagnant water. ${ }^{4}$ In this disease, there is granulomatous inflammation of the affected tissues; commonest of all are the nose, nasopharynx and the ocular conjunctiva. It occasionally involves the lips, palate, uvula, maxillary antrum, lacrimal sac, epiglottis, larynx, ear, scalp, skin, penis, vulva and vagina. Tracheobronchial involvement is very rare. The treatment of choice is surgical excision by electric diathermy or laser. In our patient tracheal rhinosporidiosis was diagnosed by means of flexible bronchoscopy as very small amount of tissue was punched out via the biopsy port of bronchoscope and sent for histopathological examination, no such dangerous bleeding was encountered. Extent of the disease in the trachea was evident in CT imaging. Virtual bronchoscopy is one of the useful modality for imaging significantly compromised airways and it is $84 \%$ sensitive with $75 \%$ specificity. ${ }^{5}$ But, it was not done in our case as the other end of the tracheal growth was visible due to its pendulous nature and mobility on respiration. Complete excision of the mass with electric cauterization was done using the rigid bronchoscope and latest general anesthesia techniques without any need of tracheostomy. Patient was discharged on medical treatment with dapsone for prevention of recurrence. ${ }^{6}$ Recurrence in the tracheobronchial lesions is unknown. Only 10\% recurrence is reported in nasal rhinosporidiosis. $^{7}$

\section{REFERENCES}

1. Seeber GR. Un neuvo esporozoario parasito del hombre: dos casos encontrades en polipos nasales. Thesis, Universidad Nacional de Buenos Aires 1900.

2. Rippon JW. Medical mycology: The pathogenic fungi and pathogenic actinomycetes (1st Ed). WB Saunders \& Co., Philadelphia, London, Toronto 1974;285-94.

3. Vukovic Z, Bobic-Radovanovic A, Latkovic Z, Radovanovic $Z$. An epidemiological investigation of the first outbreak of rhinosporidiosis in Europe. J Trop Med Hyg 1995;98:333-37.

4. Thappa DM, Venkatesan S, Sirka CS, Jaisankar TJ, Gopalkrishna, Ratnakar C. Disseminated cutaneous rhinosporidiosis. J Dermatol 1998;25:527-32.

5. Jones CM, Athanasiou T. Is virtual bronchoscopy an efficient diagnostic tool for the thoracic surgeon? Ann Thorac Surg 2005; 79:365-74.

6. Job A, Venkateswaran S, Mathan M, et al. Medical therapy of rhinosporidiosis with dapsone. J Laryngol Otol 1993;107: 809-12.

7. Fredricks DN, Jolley JA, Lepp PW, Kosek JC, Relman DA. Rhinosporidium seeberi. A human pathogen from a novel group of aquatic protistan parasites. Emerg Infect Dis 2000;6:273-82. 